\title{
Increasing myocardial infarction mortality trends in a middle-income country
}

\author{
Javier A. Balda-Canizares ${ }^{1 \#}$, Leonardo Tamariz ${ }^{2,3 \#}$, Daniel Moreno-Zambrano ${ }^{1}$, Denisse Pareja ${ }^{1,3}$, Esteban \\ Ortiz-Prado ${ }^{4}$ Alfredo Palacio ${ }^{5,6,7}$, Ana Palacio ${ }^{2,3}$ \\ ${ }^{1}$ Facultad de Ciencias Medicas, Universidad Catolica Santiago de Guayaquil, Guayaquil, Ecuador; ${ }^{2}$ Division of Population Health and Computational \\ Medicine, University of Miami, Miami, USA; ${ }^{3}$ Geriatric Research Education and Clinical Center (GRECC), Miami VA Healthcare System, Miami, \\ USA; ${ }^{4}$ Facultad de Ciencias Medicas, Universidad de las Americas, Quito, Ecuador; ${ }^{5}$ Instituto Nacional de Cardiologia Alfredo Palacio (INCAP), \\ Guayaquil, Ecuador; ${ }^{6}$ Universidad de Especialidades Espiritu Santo, Guayaquil, Ecuador; ${ }^{7}$ Cardiocentro, Manta, Ecuador \\ Contributions: (I) Conception and design: L Tamariz, A Palacio, JA Balda-Canizares, E Ortiz-Prado; (II) Administrative support: L Tamariz, D \\ Pareja, A Palacio; (III) Provision of study materials or patients: JA Balda-Canizares, D Moreno-Zambrano; (IV) Collection and assembly of data: JA \\ Balda-Canizares, L Tamariz; (V) Data analysis and interpretation: JA Balda-Canizares, L Tamariz; (VI) Manuscript writing: All authors; (VII) Final \\ approval of manuscript: All authors. \\ \#These authors contributed equally to this work. \\ Correspondence to: Leonardo Tamariz, MD, MPH. University of Miami, 1120 NW 14 ${ }^{\text {th }}$ St., Suite 967, Miami, FL 33136, USA. \\ Email: ltamariz@med.miami.edu.
}

Background: Developed countries continue to show a decrease in cardiovascular disease (CVD) mortality. Little is known about CVD mortality trends in low and middle-income countries. The aim of our study is to describe myocardial infarction (MI) mortality trends and evaluate if differences between ethnic groups and geographic regions are present among the Ecuadorians with acute MI.

Methods: We conducted a cross sectional analysis mortality national registry and included deaths related to MI between 2012 and 2016 that had complete demographic data. To describe the general population, we used the 2010 census and applied estimates as population projections. We calculated age and sex standardized MI mortality rates per 100,000. We compared trends in MI mortality rate for every ethnic group and geographic region and used linear regression to estimate predictors of the changing mortality rates.

Results: We included 18,277 MI deaths between the years 2012 and 2016. The mean age of death was $73.6 \pm 19.5$, 59\% were male and 33\% were illiterate. From 2012 to 2016, the standardized MI mortality rate increased from 51 to 157 deaths per 100,000. The most significant predictors of the increasing mortality rate were living in the coast $(\beta=0.10)$, belonging to a mixed race $(\beta=-0.033)$ and the year of death $(\beta=0.013)$.

Conclusions: Our study found a worrisome increase in MI mortality between 2012-2016 in Ecuador, a middle-income country in South America. This rapid increase seems to be driven by geographic and racial differences. A thorough evaluation of the causes of this increase has to be undertaken by the Ecuadorian health authorities.

Keywords: Cardiovascular disease (CVD); coronary artery disease; ethnical disparities; temporal trends; mortality

Submitted May 02, 2018. Accepted for publication Jun 20, 2018.

doi: $10.21037 / \mathrm{cdt} .2018 .07 .03$

View this article at: http://dx.doi.org/10.21037/cdt.2018.07.03

\section{Introduction}

In North America, the mortality of acute myocardial infarction (MI) continues to decrease (1). Several reasons explain this reduction like cardiovascular risk factor control, the prompt use of percutaneous coronary angioplasty, the use of drug eluting stents and the use of evidence-based medications in the primary and secondary prevention of 
major adverse cardiovascular events.

In South America, the epidemiologic transition is occurring (2,3). Previous reports using World Health Organization data show differing trends in MI mortality in most South American countries (4) ranging from stable (5) to a clear decrease in mortality (6). This same study showed in 2011 an unexpected increase in coronary heart disease (CHD) mortality. At the same time, recent studies show an upward increase of cerebrovascular diseases, diabetes and hypertension in Ecuador (7).

The aim of our study is to describe the recent MI mortality trends and evaluate if there are differences between ethnic groups and geographic regions among the Ecuadorians with acute MI.

\section{Methods}

\section{Study design and setting}

Ecuador is a middle-income country in South America with a population of $16,642,120$. There are four main geographical regions: the coast, the highlands, the amazon region, and the Galapagos Islands. The country has different ethnicities: Indigenous, mestizo (mixture of white and native American), Montubio (mixture of native American and black), Mulato (mixture of white and black), black or afro-descendant, and whites. From 2012 to 2016, an average of 10,144,394.6 lived in urban areas and $5,881,757.8$ lived in rural areas.

We conducted a cross-sectional analysis of the National Institute of Statistics and Census (INEC) in Ecuador. The INEC is a national registry that collects hospital discharge and mortality data. These data are collected monthly as part of the required reporting system of disease incidence and death certificates generated by every healthcare institution in the country. We used the most recent data between 20122016 to extend the trend seen in previous publications (4) and assure we only included international classification of diseases (ICD) 10 codes. The study was exempt from institutional review board regulations because of the use of publicly available de-identified data.

\section{Study population}

We identified all deaths between 2012 and 2016 and classified them as being related to a $\mathrm{MI}$ or not. We defined MI as having an ICD-10 code (code I21.x) and included both ST segment elevation MI and non-ST segment elevation MI. We also included them if they had complete demographic data. The positive predictive value of the ICD-10 for $\mathrm{MI}$ had been reported as ranging between 92-100\% (8). The INEC collects mortality from death certificates. All death certificates are collected centrally by the national identification office (Registro civil) and reported to the INEC monthly.

\section{Predictors}

We used demographic data from the INEC database. The source of demographic information comes from the national identification office as part of the ID card generation process.

We included age of death, gender, marital status classified as married if subjects lived together or were married, and self-reported ethnicity region. We classified self-reported ethnicity as mixed race (mestizo), minorities (Indigenous, Afro-Ecuadorians and Montubio) and White.

The demographic data also included a measure of health literacy defined as self-report of being able to read and, area of residency classified as urban or rural and region of the country classified as coast, highlands, islands or the Amazonic region.

We linked the INEC data with the general census. To describe the general population, we collected data from the Census of Population and Housing 2010 Poblacion (9) and applied the same percentage values to the population projections generated yearly by the INEC for each one of the 24 provinces that Ecuador is divided into (10).

\section{Statistical analysis}

We compared baseline characteristics using chi-square for categorical variables and ANOVA for continuous variables.

We calculated the crude MI mortality rate diving the number of MI deaths per year by the population in that given year and multiplying the result by 100,000 . We also calculated the standardized age and sex mortality rate and its corresponding $95 \%$ confidence interval (CI). Because the values were similar we used the former. We used the Cochran-Armitage test to calculate the $\mathrm{P}$ value for trend and determine if changes in MI mortality occurred over time.

We used the variance weighted least squares liner regression method to evaluate the contribution of each predictor to the changes in MI mortality rates. To do this we calculated the yearly mortality rate related to MI and used it as the dependent variable to calculate the beta- 
coefficient $(\beta)$ of each predictor and the corresponding $95 \%$ CI (11).

Analyses were performed using STATA 14.0 (College Station, Texas), and all significance tests were two-tailed.

\section{Results}

\section{Baseline characteristics}

Figure 1 shows the flow chart of included and excluded

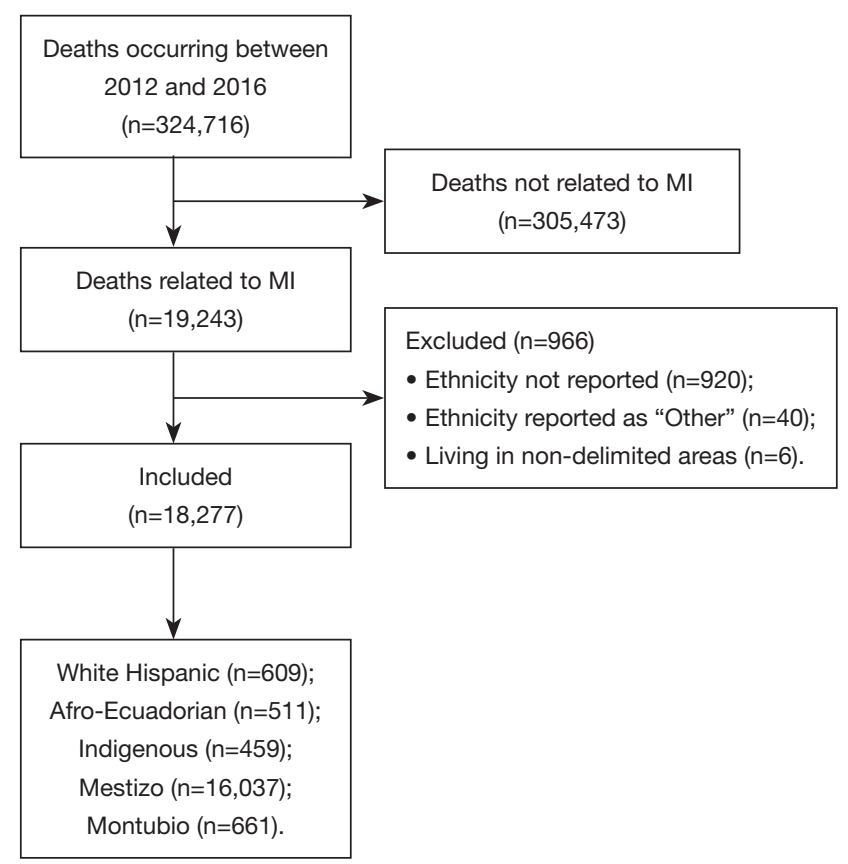

Figure 1 Flow-chart of included deaths. MI, myocardial infarction. subjects. There were 324,716 deaths between 2012 and 2016. We identified 19,243 deaths (6\%) due to MI for this study but only included 18,277 with complete predictor data.

Table 1 describes the baseline characteristics of all the 18,277 included deaths due to MI. The mean age of death was $73.6 \pm 19.5$ years, most $\mathrm{MI}$ deaths occurred in males $(59 \%)$, most deaths were reported in the coast $(66 \%)$, most lived in urban areas (82\%) and $33 \%$ of the MI deaths occurred in illiterate patients. When the entire population was stratified by year, the majority of the deaths were reported in $2016(n=5,862)$. In 2016 the deaths were older (74 years) and more likely to live in the coast (70\%).

\section{Trends in acute myocardial mortality}

Figure 2 shows the overall age and sex standardized MI mortality trends between 2012 to 2016 and Table 2 reports the standardized MI mortality rate per 100,000. Mortality rates due to $\mathrm{MI}$ increased from 51 in 2012 to 157 in 2016 per 100,000 ( $\mathrm{P}<0.01$ for trend). The majority of age and sex standardized MI deaths were seen in those older than 65 years of age and they also had the largest increase over time $(69 \%)$.

\section{Trends by ethnic group}

Table 3 and Figure 3 show the MI death rates by racial group. The majority of the deaths occurred in the mixedrace group. Those with mixed race were more likely to live in the coast (66\%) and less likely to live in urban areas (82\%). The MI mortality rates were higher among mestizos with a

Table 1 Baseline characteristics by year

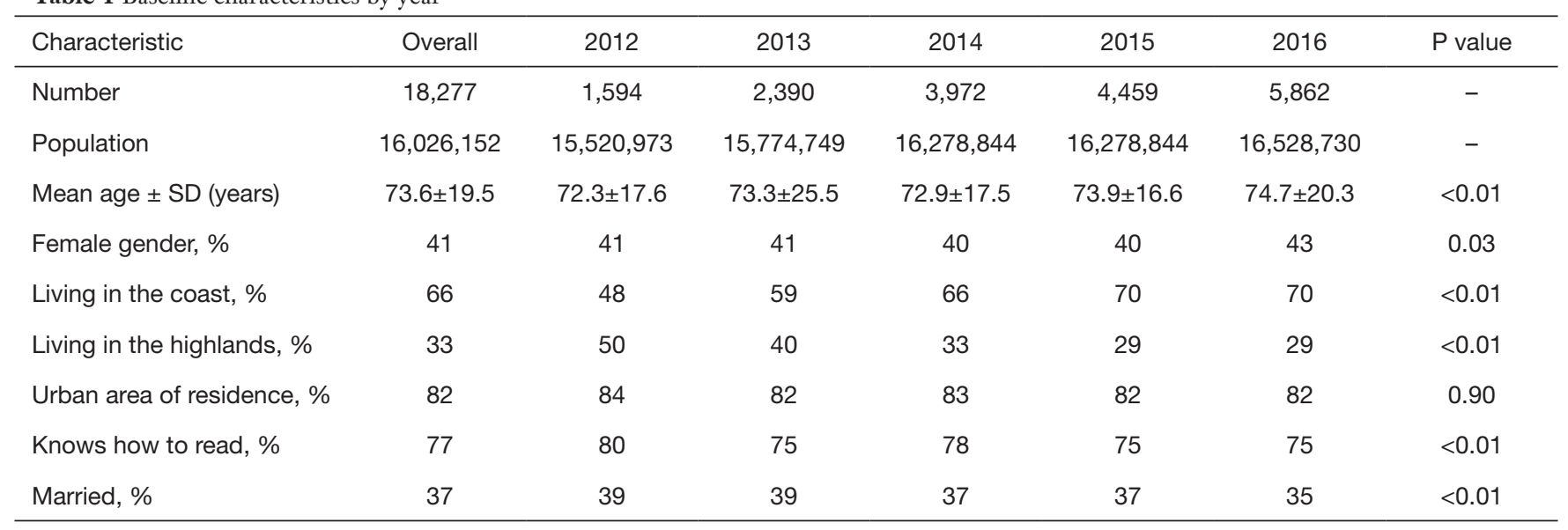


mean annual increase of 7.77 per year as opposed to other ethnicities where the mean annual rate increase was 5.04 in Montubios, 2.49 in white, 1.34 in Afro-Ecuadorians and 0.38 in indigenous.

\section{Trends by geographic region}

Table 4 and Figure 4 show the mortality rate by geographic

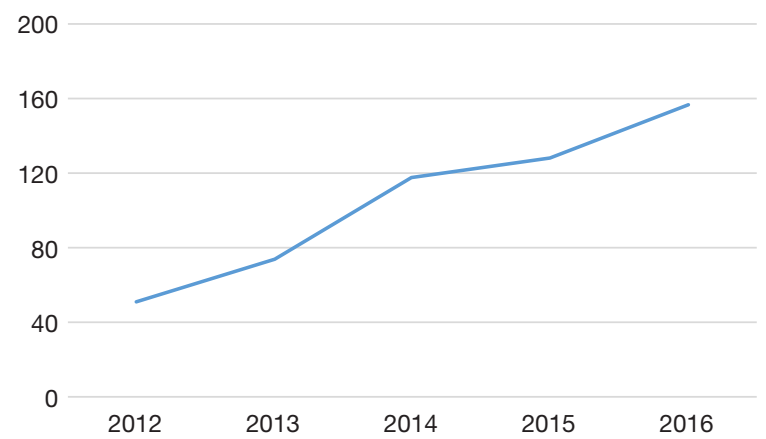

Figure 2 Age and sex standardized MI mortality rates per 100,000 between 2012-2016. MI, myocardial infarction. region. The $\mathrm{MI}$ mortality rates throughout the investigated period were higher in the coast region with a mean annual increase of 10.29 per year as opposed to other geographic regions where the mean annual rate increase was 2.68 in the highlands, 0.40 in the Amazonic region and 6.63 in the Galapagos Islands. When we stratified the coastal provinces those in the middle of the country and with higher populations had higher MI rates (Guayas, Manabi, Los Rios and Santa Elena) when compared to those in the periphery (Esmeraldas and El Oro). The number of MI discharges from the health care facilities also increased from 14 to 23 per 100,000 and this increase was not seen in other provinces.

\section{Multivariate analysis}

The statistically significant beta-coefficients $(\mathrm{P}<0.01)$ for the change in $\mathrm{MI}$ rate per year are the year $(\beta=0.013)$, living in an urban area $(\beta=0.007)$, age $(\beta=0.0007)$, being married $(\beta=0.003)$, belonging to a mixed race $(\beta=-0.033)$, male gender $(\beta=-0.011)$ and living in the coast $(\beta=0.10)$. The only non-significant $(\mathrm{P}=0.43)$ beta-coefficient was being able to

Table 2 Age and sex standardized MI mortality rates by year

\begin{tabular}{|c|c|c|c|c|c|c|}
\hline Age, years & 2012 & 2013 & 2014 & 2015 & 2016 & $P$ value \\
\hline $50-65$ & 68 [61-75] & 94 [86-103] & 148 [138-158] & 162 [151-172] & 191 [180-202] & $<0.01$ \\
\hline$>65$ & 68 [64-71] & 99 [94-104] & 157 [152-163] & 177 [171-183] & 222 [216-229] & $<0.01$ \\
\hline
\end{tabular}

Data are presented as mortality rates per 100,000 [95\% Cl]. MI, myocardial infarction.

Table 3 Characteristics of 18,277 deaths due to MI by race

\begin{tabular}{|c|c|c|c|c|}
\hline Characteristic & Overall & White & Minorities & Mixed race \\
\hline Population & $16,026,152$ & 974,890 & $3,441,422$ & $11,518,149$ \\
\hline Mean age, years & $73.6 \pm 19.5$ & $74.5 \pm 16.0$ & $73.1 \pm 28.6$ & $73.7 \pm 18.4$ \\
\hline Female gender, $\%$ & 41 & 42 & 41 & 41 \\
\hline Living in the highlands, \% & 33 & 41 & 33 & 33 \\
\hline Urban area of residence, $\%$ & 82 & 90 & 67 & 84 \\
\hline Knows how to read, \% & 77 & 89 & 56 & 78 \\
\hline Married, \% & 37 & 39 & 30 & 38 \\
\hline
\end{tabular}

MI, myocardial infarction. 


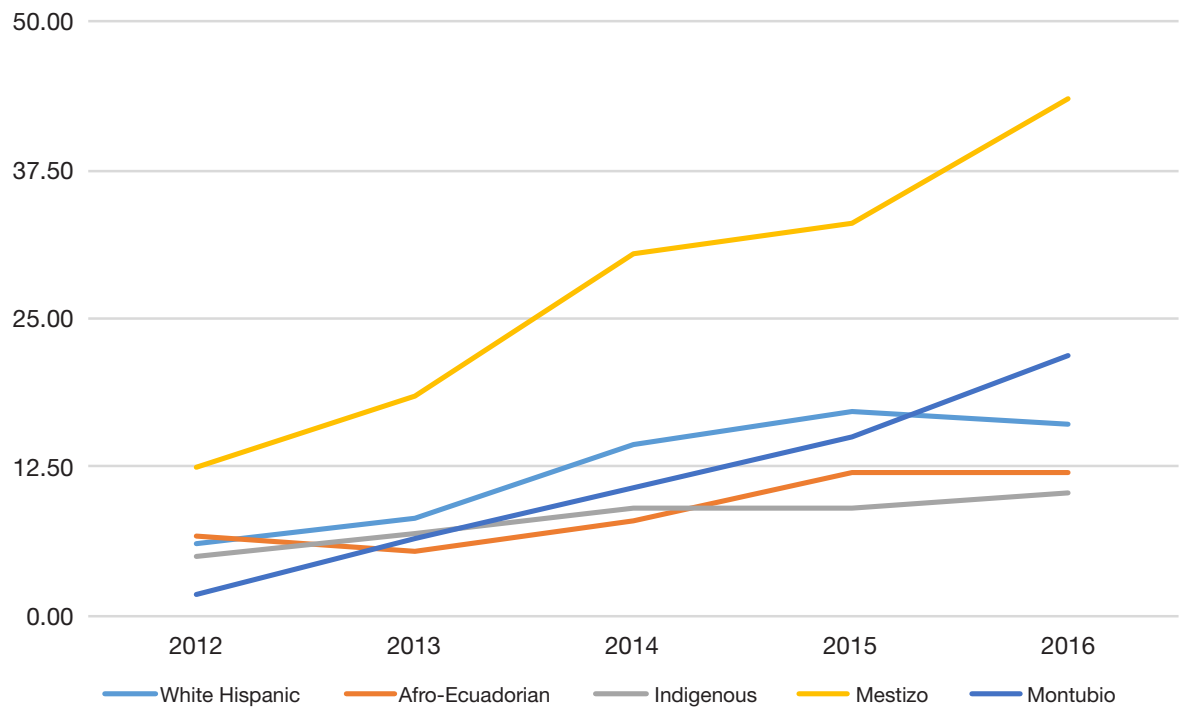

Figure 3 Age and sex standardized MI mortality rates per 100,000 between 2012-2016 by ethnicity. MI, myocardial infarction.

Table 4 Characteristics of 18,277 deaths due to MI by geographic region

\begin{tabular}{|c|c|c|c|c|c|}
\hline Characteristic & Overall & Coast & Highlands & Amazonic region & Galapagos Islands \\
\hline Population & $16,026,152$ & $7,939,923$ & $7,134,193$ & 835,731 & 28,585 \\
\hline Mean age, years & $73.6 \pm 19.5$ & $73 \pm 16.9$ & $75.27 \pm 23.6$ & $65.57 \pm 18.57$ & $67.93 \pm 7.7$ \\
\hline Female gender, \% & 41 & 41 & 42 & 27 & 20 \\
\hline Living in the highlands, \% & 33 & 0 & 100 & 0 & 0 \\
\hline Urban area of residence, \% & 82 & 88 & 72 & 75 & 93 \\
\hline Knows how to read, \% & 77 & 76 & 77 & 81 & 93 \\
\hline Married, \% & 37 & 33 & 44 & 48 & 66 \\
\hline
\end{tabular}

MI, myocardial infarction.

$\operatorname{read}(\beta=0.001)$.

\section{Discussion}

Our study found that the MI mortality rates are increasing in Ecuador, a middle-income country, and that this increase is more pronounced in the coastal region of the country. We also found that increasing age, being male, being of mixed race and living on an urban area were associated with a larger increase in mortality over time. This increase was driven mainly by geographic differences. The strengths of this study are the use of national data government sponsored data, the use of the most 5-year recent data and the small amount of missing data.

Our study has several limitations that deserve mention. First, we used an administrative data that could lead to information bias, this is particularly relevant for the validity of the cause of death. However, the covariates are subject to less information bias since this data is linked to the national ID service which assures its validity. Second, because we relied on the census, we used population projections as denominators instead of official general population numbers, which may not be an accurate representation of the population growth between 2012 and 2016 . 


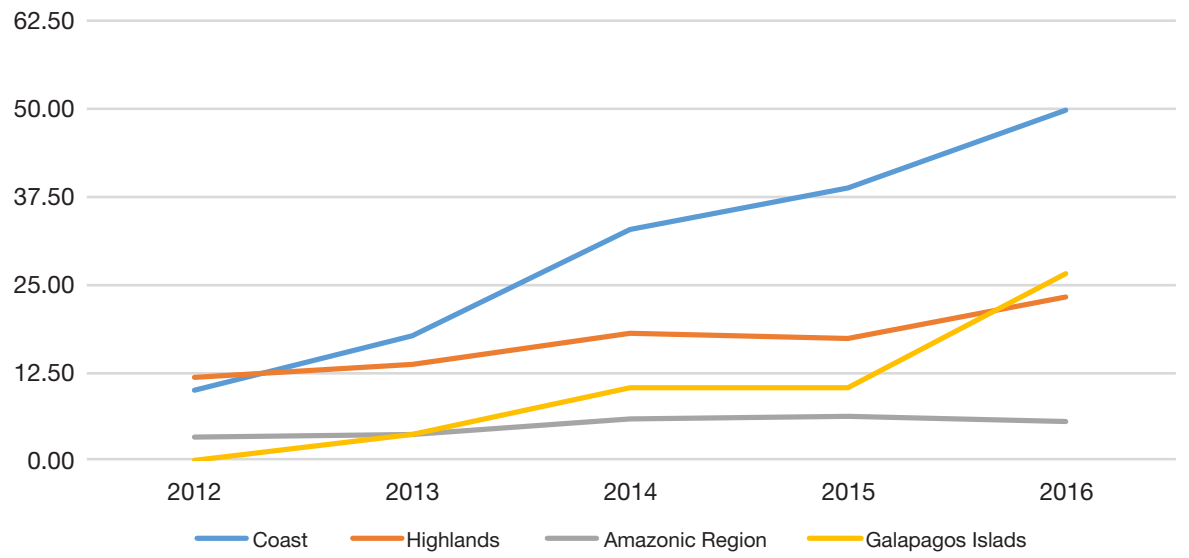

Figure 4 Age and sex standardized MI mortality rates per 100,000 between 2012-2016 by geographical region. MI, myocardial infarction.

However, this is a valid method of estimating census-based projections (12). Third, despite the improvement and standardization of formularies, non-transmittable diseases may be underreported in the rural setting.

North America has seen a clear decreasing trend in coronary artery disease mortality rate over the last decade. Pagan et al. found that the trends for Latin American countries have been more heterogeneous, however with the exception of Uruguay and Puerto Rico that experienced increase in 2011, most countries had declining or flat rates after the year 2000 (4). Of all the countries analyzed, Ecuador had the lowest mortality rate for CHD in the period of 2011-2013 (19.6/100,000 in men and 10.4/100,000 in women). Our study which aimed at evaluating the presence of disparities in CHD mortality rate within Ecuador, extends the evaluation period of the Pagan et al. study and documents a significant increase in MI mortality in the 2012-2016 period.

Potential explanations for this sharp change could be related to changes in access to health care, changes in the use of evidence-based therapies, changes in the prevalence of cardiovascular risk factors or migratory related changes in the population. Other potential explanations include changes in gross domestic product leading to lower health funding and a decrease in the availability of specialized medications. Others have found that changes in sociopolitical factors are related to increased cardiovascular mortality. Our study could not evaluate this causes for the increasing MI rates. However, clues are that most of the increase was explained by the differential increase in the coastal areas and among Ecuadorians of mixed race. An additional finding of interest is that the second highest mortality rate occurred in the Galapagos Islands.

In our study, the majority of the deaths occurred in the coast or the highlands. Besides having densely populated areas, we found that the mean age of death for MI in these two regions is considerably higher than in lower populated regions. This higher prevalence could be related to subsequent survival, which may lead to an increased prevalence of chronic diseases (of later onset) such as diabetes and hypertension that also contribute to the development MI.

The majority of deaths occurred in the mixed-race group. However, this is the largest population of the country. Being a minority was a clear predictor of the increase in MI mortality. A potential explanation for this are social determinants of health. Social determinants have been associated with poor outcomes in south America (13-15) and this might play a more important factor in South America were resources are not ample.

On the other hand, Indigenous Ecuadorians are another minority that faces socioeconomic difficulties (considering their low literacy levels). Despite this, the mean age of death secondary to MI is high in relation to other ethnic groups. We attribute this to a lesser exposure to an urban lifestyle. Their diet which is rich in cereals and vegetables has not shifted to the high fat/calorie intake seen in the urban setting. Also, the diminished access to public transportation, and technology such as washing machines, heaters, etc. makes them walk miles in order to wash their clothes in rivers, collect wood for heat, work the land and harvest their own products; leading to an increased daily physical activity, preventing the physiopathologic processes that lead to diabetes, atherosclerosis and MI. Studies in other native 
American descendant communities have evidenced and increased prevalence of metabolic syndrome and other nontransmittable diseases after migrating to developed countries.

From the same perspective, the rapid increasing MI mortality rates seen in mestizos may be attributable to an urban lifestyle in combination with the previously described increase in the survival from early onset conditions (mainly infectious).

\section{Conclusions}

In conclusion, lower rates seen in less populated regions (Amazonic and Galapagos Islands) may mask the high prevalence of infectious diseases as cause of death. Addressing other causes of death may increase the mean age of death seen in this region. The rapid MI mortality rate increase seen in highly populated regions, mainly in mestizos should be addressed by fomenting preventive measures such as an adequate diet and moderate to high levels of physical activity. Finally granting easier access to medical treatment for minorities such as Afro-Ecuadorians may increase mean age MI mortality presentation.

\section{Acknowledgements}

None.

\section{Footnote}

Conflicts of Interest: The authors have no conflicts of interest to declare.

\section{References}

1. Benjamin EJ, Blaha MJ, Chiuve SE, et al. Heart Disease and Stroke Statistics-2017 Update: A Report From the American Heart Association. Circulation 2017;135:e146-603.

2. Stevens G, Dias RH, Thomas KJ, et al. Characterizing the epidemiological transition in Mexico: national and subnational burden of diseases, injuries, and risk factors. PLoS Med 2008;5:e125.

3. Gonzalez-Gonzalez C, Samper-Ternent R, Wong R, et al. Mortality inequality among older adults in Mexico: the combined role of infectious and chronic disease. Rev Panam Salud Publica 2014;35:89-95.

4. Pagan E, Chatenoud L, Rodriguez T, et al. Comparison of Trends in Mortality from Coronary Heart and
Cerebrovascular Diseases in North and South America: 1980 to 2013. Am J Cardiol 2017;119:862-71.

5. Nazzal C, Harris JE. Lower incidence of myocardial infarction after smoke-free legislation enforcement in Chile. Bull World Health Organ 2017;95:674-82.

6. Baena CP, Chowdhury R, Schio NA, et al. Ischaemic heart disease deaths in Brazil: current trends, regional disparities and future projections. Heart 2013;99:1359-64.

7. Moreno-Zambrano D, Santamaria D, Ludeña C, et al. Enfermedad Cerebrovascular en el Ecuador: Análisis de los Últimos 25 Años de Mortalidad, Realidad Actual y Recomendaciones. Revista Ecuatoriana de Neurologia 2016;25:1-3.

8. Patel AB, Quan H, Welsh RC, et al. Validity and utility of ICD-10 administrative health data for identifying STand non-ST-elevation myocardial infarction based on physician chart review. CMAJ Open 2015;3:E413-8.

9. Instituto Nacional de Estadistica y Censos. Poblacion y Demografia. Censos I. 2017. Available online: http://www. ecuadorencifras.gob.ec/estadisticas/

10. Instituto Nacional de Estadistica y Censos. Proyecciones Poblacionales, Censos I. 2017. Available online: http:// www.ecuadorencifras.gob.ec/censo-de-poblacion-yvivienda/

11. Tu YK, Chien KL, Burley V, et al. Unravelling the effects of age, period and cohort on metabolic syndrome components in a Taiwanese population using partial least squares regression. BMC Med Res Methodol 2011;11:82.

12. Aickin M, Dunn CN, Flood TJ. Estimation of population denominators for public health studies at the tract, gender, and age-specific level. Am J Public Health 1991;81:918-20.

13. Arroyave I, Burdorf A, Cardona D, et al. Socioeconomic inequalities in premature mortality in Colombia, 19982007: the double burden of non-communicable diseases and injuries. Prev Med 2014;64:41-7.

14. Barreto SM, Miranda JJ, Figueroa JP, et al. Epidemiology in Latin America and the Caribbean: current situation and challenges. Int J Epidemiol 2012;41:557-71.

15. Balfour PC Jr, Ruiz JM, Talavera GA, et al. Cardiovascular Disease in Hispanics/Latinos in the United States. J Lat Psychol 2016;4:98-113.

Cite this article as: Balda-Canizares JA, Tamariz L, MorenoZambrano D, Pareja D, Ortiz-Prado E, Palacio A, Palacio A. Increasing myocardial infarction mortality trends in a middleincome country. Cardiovasc Diagn Ther 2018;8(4):493-499. doi: 10.21037/cdt.2018.07.03 